\title{
Lake Nyos disaster, Cameroon, 1986: the medical effects of large scale emission of carbon dioxide?
}

\author{
Peter J Baxter, M Kapila, D Mfonfu
}

\begin{abstract}
Carbon dioxide was blamed for the deaths of around 1700 people in Cameroon, west Africa, in 1986 when a massive release of gas occurred from Lake Nyos, a volcanic crater lake. The clinical findings in 845 survivors seen at or admitted to hospital were compatible with exposure to an asphyxiant gas. Rescuers noted cutaneous erythema and bullae on an unknown proportion of corpses and $161(19 \%)$ survivors treated in hospital; though these lesions were initially believed to be burns from acidic gases, further investigation suggested that they were associated with coma states caused by exposure to carbon dioxide in air.
\end{abstract}

The disaster at Lake Nyos and a similar event at Lake Monoun, Cameroon, two years previously provide new information on the possible medical effects of large scale emissions of carbon dioxide, though the presence of other toxic factors in these gas releases cannot be excluded.

\section{Introduction}

On 21 August 1986 about 1700 people were killed by a massive release of gas from Lake Nyos, a volcanic crater lake situated in a remote, mountainous part of north west Cameroon, west Africa. Though the gas is believed to have been volcanic, its precise composition and mechanism of release remain uncertain. Volcanic gases typically contain water vapour, carbon dioxide, sulphur dioxide, hydrogen sulphide, hydrogen chloride, hydrogen fluoride, and carbon monoxide.' Carbon dioxide, however, was the only gas detected in samples of lake water, ${ }^{23}$ suggesting that this was the predominant if not only gas released. In a strikingly similar event in August 1984 at Lake Monoun, about $100 \mathrm{~km}$ south of Lake Nyos, 37 people were killed by a cloud of gas also believed to have been carbon dioxide. ${ }^{4}$ To our knowledge catastrophic large scale emissions of carbon dioxide from natural or industrial sources have not been reported before, though an eruption of gas from the Sinila volcano, Dieng Plateau, Indonesia, caused 139 deaths in $1979 .{ }^{5}$ Clinical information from these previous events is $s r$ irse, and the disaster at Lake Nyos provided an op:oi unity to study the effects of such gas releases in more detail. We summarise the main clinical findings to draw attention to this newly recognised hazard in volcanic areas and to the possible effects on populations of large scale emissions of carbon dioxide.

Ministère de la Santé

Publique, Yaoundé,

Cameroon

D Mfonfu, MD, chief of

epidemiology

Correspondence to: Dr Baxter.

BrMed f 1989;298:1437-41

\section{Background and findings}

Lake Nyos is about $1.9 \mathrm{~km}$ long, $1.2 \mathrm{~km}$ wide, and $200 \mathrm{~m}$ deep; less than $3 \mathrm{~km}$ to the north the valley floor is more than $250 \mathrm{~m}$ below the surface level of the lake. ${ }^{23}$ The release occurred between 9 and $10 \mathrm{pm}$ on a calm night, and the gas flowed northwards, causing heavy loss of life in the settlements of Nyos, Cha, and Subum, and along valleys in a sparsely populated farming area some $20 \mathrm{~km}$ long by $15 \mathrm{~km}$ wide ${ }^{6}$ (fig 1 ). Most of the native population were either subsistence farmers or Fulani cattle raisers; many cattle as well as other animals were killed. Survivors near the lake recalled hearing wind or animals being disturbed and some reported a smell of gunpowder or rotten eggs before suddenly losing consciousness. News of the event was slow to emerge, and when a rescue team entered the area 36 hours later it came upon an awesome scene. One of us $(\mathrm{DM})$ was a member of the team.

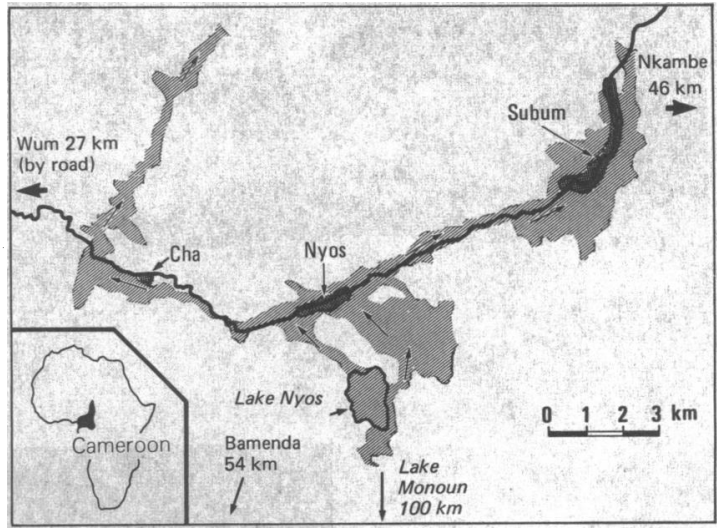

FIG 1-Direction of flow of gas (arrows; stippled area) from Lake Nyos into adjacent valleys

\section{SURVIVORS}

From at most about 5000 survivors living in the affected area, 548 were admitted to the two hospitals in Wum and Nkambe; a further 297 attended the hospitals over subsequent weeks. The cardinal presenting symptoms and signs in these two groups were collated from hospital records (table I) and showed a similar pattern ${ }^{6}$ except that virtually all the patients who were admitted, including those with skin lesions, were believed to have lost consciousness. Consciousness was seemingly lost for hours, and certainly overnight for many victims, though cultural and

TABLE I-Main clinical findings in 845 survivors of gas eruption from Lake Nyos attending $(n=297)$ or admitted $(n=548)$ to hospital for treatment

\begin{tabular}{lc|lc}
\hline & $\begin{array}{c}\text { No }(\%) \text { of } \\
\text { victims }\end{array}$ & & $\begin{array}{c}\text { No }(\%) \text { of } \\
\text { victims }\end{array}$ \\
\hline Cough & $262(31)$ & Limb swelling & $85(10)$ \\
Haemoptysis & $25(3)$ & Vomiting & $42(5)$ \\
Dyspnoea & $42(5)$ & Diarrhoea & $42(5)$ \\
Eye irritation & $42(5)$ & Headache & $220(26)$ \\
Skin lesions resembling burns & $161(19)$ & Weakness/malaise & $93(11)$ \\
Limb weakness & $51(6)$ & Fever & $101(12)$ \\
& & & \\
\hline
\end{tabular}

Total No of records $=845$; total No of attendees $=870$; information missing in 25 cases. 

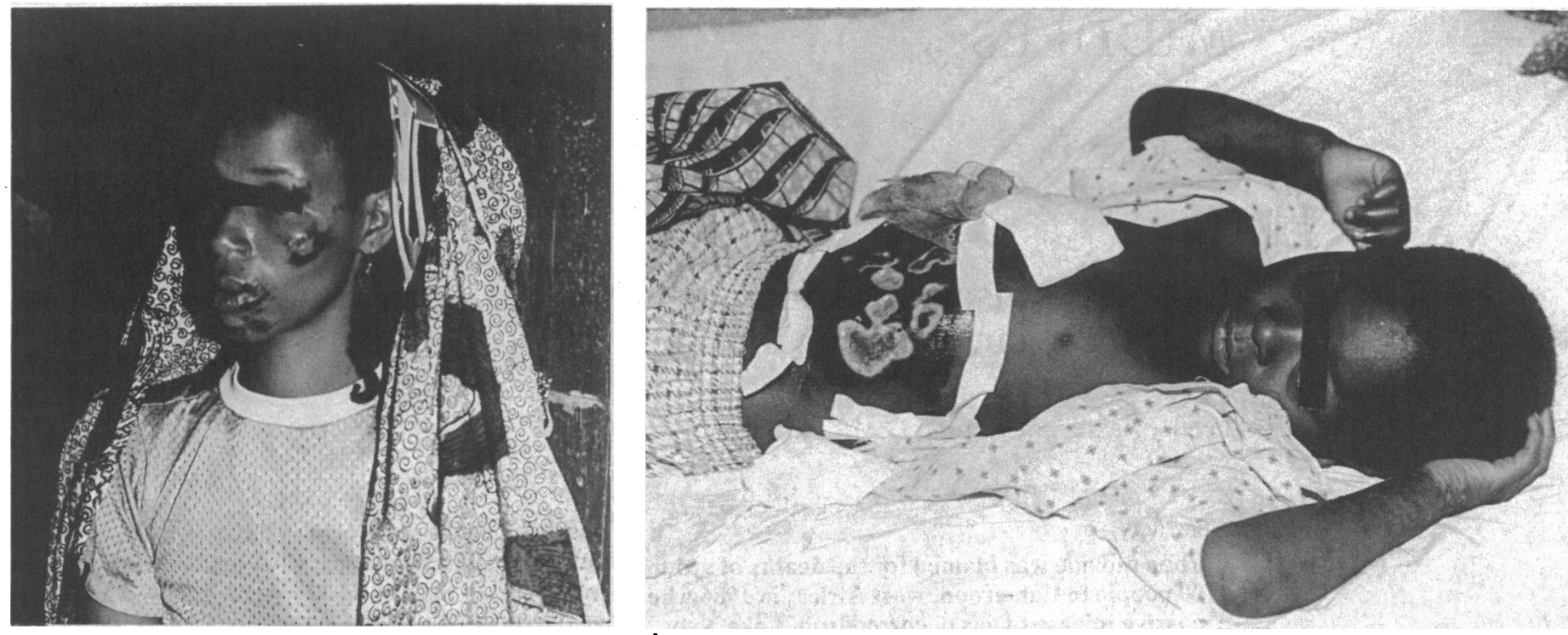

d

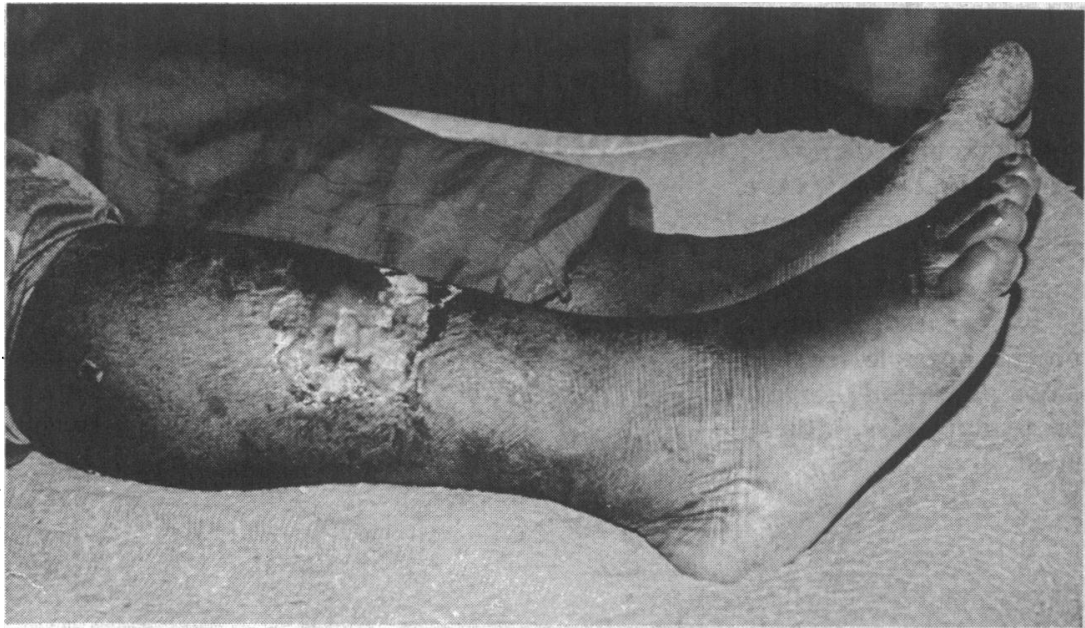

b

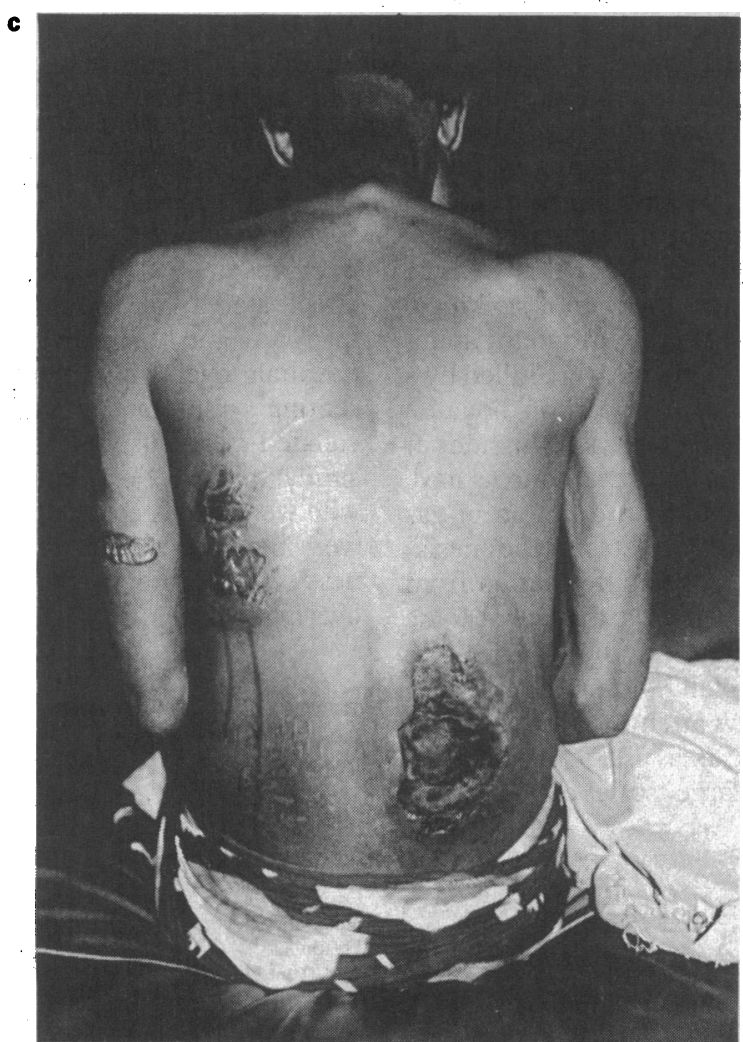

FIG 2 (a-e)-Cutaneous lesions seen during second and third days after release of gas from Lake Nyos. (Photographs by DM)

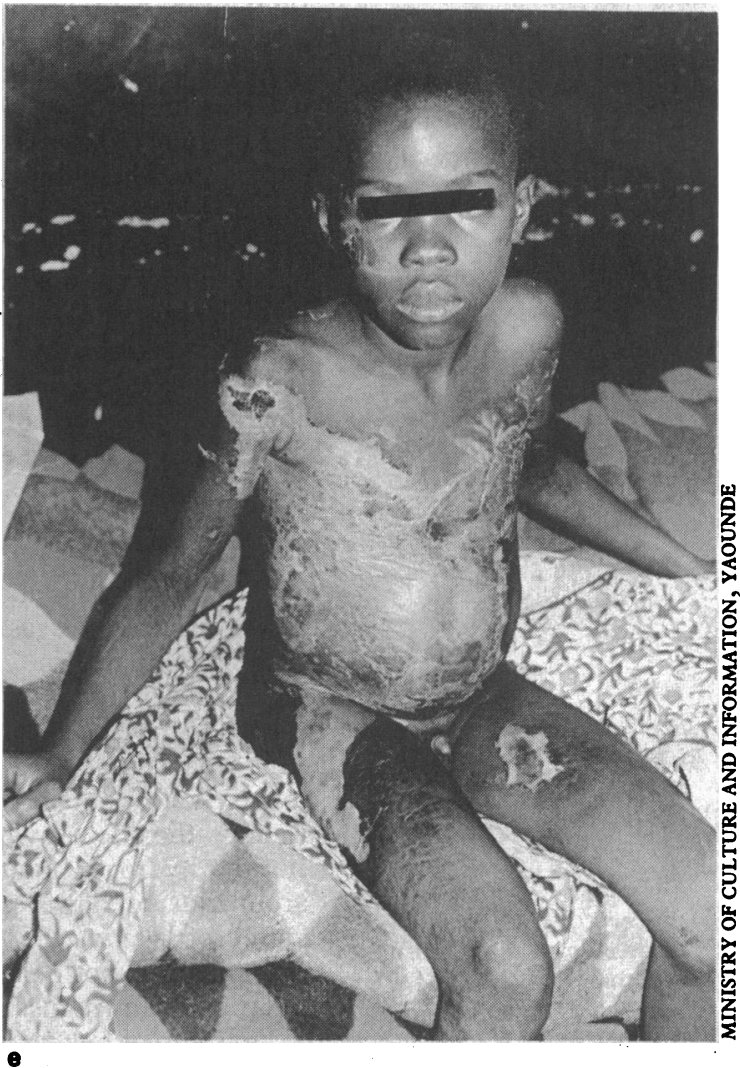

language difficulties made detailed history taking mostly impossible. Cough was a frequent complaint (262 cases; 31\%), but difficulty with breathing was recorded in only 42 cases (5\%); haemoptysis was also uncommon. Respiratory problems were treated with antibiotics, but three patients died of pneumonia. Only 42 patients had conjunctivitis or severe eye symptoms.

The commonest physical abnormalities seen on examination were erythema and other skin changes resembling burns (161 cases; 19\%). In 36 of the hospital inpatients blistering or ulceration of the skin without underlying muscle necrosis was present which was initially believed to be due to the effects of acidic volcanic gases. These lesions were most often present on the face (table II) and mainly over the zygomatic region (fig $2 a$ ) but in other cases on the leg (fig $2 b$ ) or abdomen or back (fig $2 c-e$ ). Only five patients attributed their lesions to burns. Among those admitted to and attending the hospitals 51 patients $(6 \%)$ had weakness of arms or legs, including footdrop and 
TABLE II-Distribution of sites of superficial and deep skin lesions in 548 survivors admitted to hospital

\begin{tabular}{lc|lc}
\hline & No of lesions & & No of lesions \\
\hline Face: & & Abdomen & 8 \\
Zygoma & 84 & Back & 1 \\
Other & 36 & Arm & 7 \\
Neck & 2 & Leg & 18 \\
Chest & 2 & Over body & 3 \\
\hline
\end{tabular}

wristdrop, together with associated oedema ( 85 cases; $10 \%)$. Less specific complaints such as generalised body pains and headache were frequent, and 101 patients $(12 \%)$ had fever (malaria was endemic in the area). Diarrhoea and dehydration were uncommon. In the hospital at Nkambe many patients were found to have transient proteinuria. There were seven miscarriages at under 20 weeks' gestation and four stillbirths, one at 32 weeks and three near term. Loss of smell or taste was not reported, but several patients complained of unilateral hearing loss after the event. The pattern of illness was the same regardless of where the survivors had been at the time of the release.

Most of the skin lesions were superficial and healed within two weeks. Patients with limb weakness also were improved within two weeks. There was no evidence of gross damage to the central nervous system or persistent respiratory disability in the inpatients; most of the survivors went to live in refugee camps and a year later were not reported to be suffering from mental or respiratory problems referable to the disaster.

CORPSES

The appearance and disposition of the corpses were not systematically recorded and necropsies were not performed before burial by the fourth day after the gas release; however, many (proportion unknown) had prominent skin bullae (figs 3 and 4). The gross appearances of the dead cattle, including the skin, showed nothing abnormal.

Foreign scientists and health workers invited by the Cameroon government did not arrive until at least one week after the release. A United States medical team performed a necropsy on a 30 year old man from Nyos who had died two days after admission to hospital at Wum (the body had been embalmed). The cause of death was pneumonia. The team exhumed a male victim at Subum, and the decomposing corpse showed evidence of pulmonary congestion and oedema. The carcase of a bull was also examined at Subum but the findings were non-specific. Additional material collected by Cameroonian doctors from a 30 year old man who died on 27 August showed congestion of the lungs and no other gross changes. These findings were in keeping with death from exposure to an asphyxiant gas. ${ }^{3}$ The Japanese team performed a necropsy on a

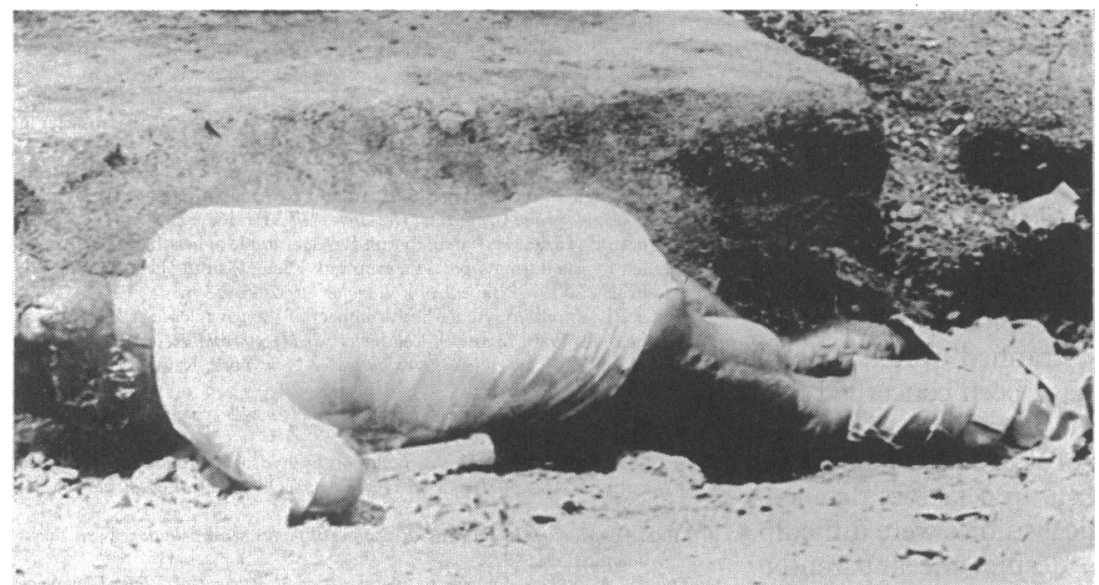

FIG 3-Dead man found in Nyos village

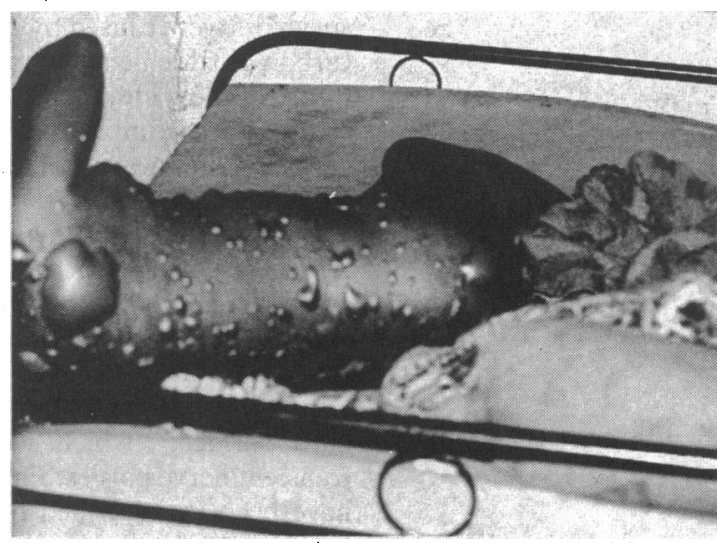

FIG 4-Dead woman found inside house. (Photograph by DM)

man who had died 90 minutes previously in Cha village on 30 August. The team found massive pulmonary congestion and an increased sulphate concentration in skin samples, suggesting that sulphur dioxide had been inhaled; this result, however, may have been due to the use of contaminated formaldehyde solution for preserving the samples or because the control skin collected in Japan was inappropriate (Japanese International Disaster Relief Team, unpublished observations).

\section{Discussion}

The history of sudden loss of consciousness with coma lasting for hours followed by rapid recovery was more compatible with exposure to a high concentration of an asphyxiant than an irritant gas (or gases). ${ }^{7}$ Irritant gases such as sulphur dioxide or hydrogen chloride would be more likely to have caused pulmonary oedema and severe irritation of the eyes and mucous membranes than was found, and these effects and their clinical sequelae would have persisted for longer than the 36 hours that it took before survivors reached hospital. The most likely explanation for the respiratory problems in a minority of patients was pulmonary oedema and consolidation due to prolonged coma, especially as most resolved rapidly after antibiotics.

The main asphyxiant volcanic gases are carbon dioxide, carbon monoxide, and hydrogen sulphide, but high concentrations of hydrogen sulphide can be excluded, as this agent is also very irritant. ${ }^{89}$ Nevertheless, some survivors did report smelling gunpowder or rotten eggs, so that small amounts of sulphur dioxide and hydrogen sulphide cannot be dismissed. Further confirmation that acidic gases were not present in appreciable amounts was the absence of damage to foliage near the lake or where people died; concentrations of sulphur dioxide, hydrogen chloride, or hydrogen fluoride high enough to be lethal to man would have severely damaged plants. ${ }^{10} 11$ Carbon dioxide was most likely to have been the main if not only gas released, as indicated by its abundance in the lake water together with normal amounts of sulphur and halides found in samples taken at depth after the event. ${ }^{2}$ In addition, carbon dioxide is 1.5 times denser than air at normal temperature and would have readily flowed down into the valleys. Coma lasting for hours and the skin lesions recorded, however, have not been reported in victims of carbon dioxide poisoning, and doubt must remain that all the findings can be attributed to this gas alone.

Carbon dioxide has been tried as a human and experimental anaesthetic agent $t^{1213}$ and used in the treatment of mental withdrawal states ${ }^{14}$ in mixtures of air or oxygen. A mixture of $30 \%$ carbon dioxide in air induces anaesthesia, but adverse effects such as convulsions preclude its use in surgery. ${ }^{15}$ We speculate that the states of prolonged coma reported by the 
survivors were caused by anaesthetic concentrations of carbon dioxide being formed as the gas mixed with air during its flow into the valleys and that because it was a calm night the mixture remained suspended in topographical hollows until dispersed by winds or heat from the sun. As in carbon dioxide narcosis in patients with respiratory disease, spontaneous recovery and return to consciousness would be expected once the arterial $\mathrm{pH}$ reverted to normal. ${ }^{16}$

Some of the skin lesions - for example, those over the cheek bones - may have been caused by a combination of pressure and hypoxia from lying comatose on a hard surface, ${ }^{17}$ which would also account for the transient nerve palsies. Falling near fires (which would have been extinguished by carbon dioxide) may also have occurred, but we could not find such obvious explanations for the widespread erythema or the bullae noted. Erythematous lesions which may progress to intraepidermal or subepidermal vesicles or bullae with sweat gland necrosis have been reported in coma due to carbon monoxide poisoning ${ }^{18} 19$ and drug intoxication, particularly with barbiturates ${ }^{20-22}$; the mechanism of their development is conjectural, though pressure, hypoxia, and a direct toxic effect have all been cited. Theoretically carbon monoxide is not likely to have been a substantial component of the gas, and as it is no denser than air at normal temperature, it would not have flowed into the valleys. The degree of blistering also was not typical of the smaller, more discrete lesions usually reported in carbon monoxide poisoning.

The pathophysiology of coma induced by carbon dioxide has not been described, but carbon dioxide increases cerebral blood flow in the short term ${ }^{23}$; the remarkable absence of clinical central nervous system injury in survivors suggests that it might have had a protective effect in prolonged coma. The effect of high concentrations of carbon dioxide on thermoregulation in humans is uncertain, but it might well eliminate shivering and peripheral vasoconstriction. As the ambient night temperature in the area in August is around $15^{\circ} \mathrm{C},{ }^{24}$ some degree of hypothermia is likely to have occurred, and this may have been a factor in the erythema ${ }^{25}$ as well as contributing to mortality. Unlike human skin, animal skin does not blister, so that the absence of bullae on the dead cattle is of no relevance.

On their arrival at the scene of the Lake Monoun incident at 630 am rescuers observed a misty cloud which did not disperse until three to four hours later, when they examined the bodies and noted erythematous and bullous skin lesions. ${ }^{+}$Most of the victims had been overcome soon after 3 am on a $200 \mathrm{~m}$ stretch of road near the lake. Six months after the event Sigurdsson et al found that carbon dioxide with a small amount of methane still effervesced from deep water samples, and they concluded that carbon dioxide had been the lethal gas. ${ }^{+}$

In the incidents at Lake Nyos and Lake Monoun the possibility that other gases and toxic chemicals in addition to carbon dioxide were released cannot definitely be excluded. Le Guern et al believe that a volcanic eruption was the cause of the gas release at Lake Nyos, ${ }^{5}$ but this has been strongly disputed by those who favour a limnological hypothesis for both events. ${ }^{26}$ In that hypothesis carbon dioxide from an underlying volcanic source built up slowly over time in the lower layers of the two lakes and was released in a sudden degassing of the stratified waters. Both mechanisms, however, may have been concerned if a volcanic event had triggered the degassing.

Because of the remoteness of the areas where these incidents occurred and local cultural factors detailed pathological and epidemiological studies were difficult or impossible. For example, despite the apparently rapid and complete recovery of the survivors, sub- clinical neurological damage with cognitive impairment may have resulted from asphyxia, but it was not practicable to investigate this further. After a catastrophic gas release, investigations should be begun at the scene and in hospital immediately, with coordinated epidemiological, toxicological, and pathological studies of the dead and survivors. Acidic volcanic gases can be distinguished from carbon dioxide at necropsy, as they cause severe inflammation of the airways and pulmonary oedema. Inhalation of carbon monoxide and nitrogen oxides produces carboxyhaemoglobinaemia and methaemoglobinaemia, respectively. Raised concentrations of sulphide ion in blood or thio compounds in urine are detectable after exposure to hydrogen sulphide ${ }^{27}$ 28; fluoride concentrations in urine may reflect exposure to hydrogen fluoride. Any of these gases might be emitted in a volcanic eruption. Histopathological examination of the skin and biochemical analysis of the bullae fluid would help determine the cause of the dermal lesions. Observations on injury to animals and vegetation and damage to dwellings and the environment in general should be correlated with the effects found in humans. Further description of the investigations required is beyond the scope of this paper, but an outline approach for volcanic eruptions is given elsewhere. ${ }^{29}$

Future studies at Lake Nyos may clarify understanding of the mechanisms concerned in the gas release there, including the feasibility of monitoring for future devastating releases. Engineering methods for safely lowering the level of the lake or degassing its lower layers have been proposed as preventive measures. ${ }^{30}$ The catastrophes at Lake Nyos, Lake Monoun, and Dieng, Indonesia, point to large scale emissions of carbon dioxide as a newly recognised hazard in volcanic areas. Gas releases on the scale of these events (the amount of gas from Lake Nyos may have exceeded a quarter of a million tonnes) may have occurred elsewhere, but unless heavy loss of life had ensued they would go unrecorded and leave no geological trace. With the growth of populations in volcanic areas the threat of future catastrophes due to gases from either volcanoes or crater lakes must be considered by emergency planners, even though such events are seemingly rare and difficult to predict.

We thank Professor L Kaptué and Dr G Ngufor for their collaboration and Dr S J Freeth for fig 1. Professor A Gresham and Dr G Park provided valuable insights and commented on an earlier draft of this paper. We are also indebted to the following for their advice: Dr $\mathrm{K} \mathrm{J}$ Collins, I Hymes, A Newman Taylor, R Pye, T Shallice, and I Wilkinson; Professors W R Keatinge and C McDonald; Father F ten Horn; and Mr D Zeitlyn. We thank the Cameroon government; the Overseas Development Administration Disaster Unit; the British Embassy, Yaoundé; and the British Red Cross Society for their support.

1 Thorarinsson S. On the damage caused by volcanic eruptions with special reference to tephra and gases. In: Sheets PD, Grayson DK, eds. Volcanic
(n) reference to tephra and gases. In: Sheets PD, Grayson DK, eds. Volcaic
activity and human ecology. New York: Academic Press, 1979:125-59. 2 activity and human ecology. New York: Academic Press, 1979:125-59.

2 Freeth SJ, Kay RLF. The Lake Nyos gas disaster. Nature 1987;325:104-5.
3 Kling GW, Clark MA, Compton HR, et al. The 1986 Lake Nyos gas disaster in Cameroon, west Africa. Science 1987;236:169-75.

4 Sigurdsson H, Devine JD, Tchoua FM, Presser TS, Pringle MKW, Evans WC. Origin of the lethal gas burst from Lake Monoun, Cameroun. Journal of Volcanology and Geothermal Research 1987;31:1-16.

5 Le Guern F, Tazieff H, Faivre Pierret R. An example of health hazard: people killed by gas during a phreatic eruption: Dieng Plateau (Java, Indonesia), February 20 1979. Bulletin of Volcanology 1982;45:153-6.

6 Baxter PJ, Kapila M. Acute health impact of the gas release at Lake Nyos, Cameroon, 1986. Journal of Volcanology and Geothermal Research (in press). Henderson Y, Haggard HW. Noxious gases. New York: Reinhold Publishing
Co, 1943 . Co, 1943.

8 World Health Organisation. E sulphide. Geneva: WHO, 1981

9 McCabe LC, Clayton GD. Air pollution by hydrogen sulfide in Poza Rica, Mexico. Archives of Industrial Hygiene and Occupational Medicine 1952;6: 199-213.

10 Mudd JB, Kozlowski TT, eds. Responses of plants to air pollution. New York: Academic Press, 1975. 11 Thomas MD. Gas damage to plants. Annual Review of Plant Physiology
1951;2:293-322. 
12 Prys-Roberts C. Hypercapnia. In: Gray TC, Nunn JF, Utting JE, eds. General anaesthesia. Vol 1. 3rd ed. London: Butterworths, 1980:435-60.

13 Eisele JH, Eger EI, Muallem $M$. Narcotic properties of carbon dioxide in the dog. Anesthesiology 1967;28:856-65.

14 Loevenhart AS, Lorenz WF, Waters RM. Cerebral stimulation. $7 A M A$ 1929;92:880-3.

15 Seevers MH. The narcotic properties of carbon dioxide. New York State Medical fournal 1944;44:597-602.

16 Westlake EK, Simpson T, Kaye M. Carbon dioxide narcosis in emphysema. Qf Med 1955;24:155-73.

17 Arndt KA, Mihm MC, Parrish JA. Bullae: a cutaneous sign of a variety of neurologic diseases. $\mathcal{F}$ Invest Dermatol 1973;60:312-20

18 Drinker CK. Carbon monoxide asphyxia. London: Oxford University Press, 1938.

19 Meigs JW, Hughes JPW. Acute carbon monoxide poisoning. An analysis of one hundred five cases. Archives of Industrial Hygiene and Occupational Medicine 1952;6:344-56

20 Mandy S, Ackerman AB. Characteristic traumatic skin lesions in druginduced coma. FAMA 1970;213:253-6.

21 Beveridge GW, Lawson AAH. Occurrence of bullous lesions in acute barbiturate intoxication. BrMed f 1965; ; :835-7.

22 Leavell UW, Farley $\mathrm{CH}$, McIntyre JS. Cutaneous changes in a patient with carbon monoxide poisoning. Arch Dermatol 1969:99:429-33.
23 McDowall DG. Cerebral blood flow. In: Gray TC, Nunn JF, Utting JE, eds General anaesthesia. Vol 1. 3rd ed. London: Butterworths, 1980:657-84.

$24 \mathrm{Kling} \mathrm{GW}$. Seasonal mixing and catastrophic degassing in tropical lakes, Cameroon, west Africa. Science 1987;237:1022-4.

25 Maclean D, Emslie-Smith D. Accidental hypothermia. Oxford: Blackwell Scientific, 1977.

26 Sigurdsson H. Lethal gas bursts from Cameroon crater lakes. EOS 1987:68: 570-3.

27 McAnalley BH, Lowry WT, Oliver RD, Garriott JC. Determination of inorganic sulfide and cyanide in blood using specific ion electrodes: application to the investigation of hydrogen sulfide and cyanide poisoning f Anal Toxicol 1979;3:111-3.

28 van Doorn R, Leijdekkers CPMJM, Henderson PT, Vanhoorne M, Vertin PG. Determination of thio compounds in urine of workers exposed to carbon disulfide. Arch Environ Health 1981;36:289-97.

29 Baxter PJ, Bernstein RS, Buist AS. Preventive health measures in volcanic eruptions. Am J Public Health 1986; 76(suppl):84-90.

30 Sigvaldasson G. Conclusions and recommendations on the UNESCO meeting, Yaoundé, March 23, 1987. Fournal of Volcanology and Geothermal Research (in press).

(Accepted 8 March 1989)

\title{
Profile of the GMC
}

\section{Overseas doctors: diminishing controversy}

\author{
Richard Smith
}

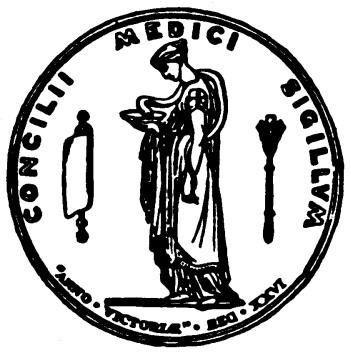

Fifteen years ago anxiety over the standard of overseas qualified doctors was one of the factors that led to the Merrison inquiry into the regulation of the medical profession. ${ }^{1}$ At the same time many overseas doctors thought that the General Medical Council gave them a raw deal and resented that they were not better represented on the council. Now there is less anxiety over the standards of overseas doctors registered by the council but slowly growing concern about the number of doctors from the European Community who are coming to Britain to practise. The concern remains, however, that overseas doctors are underrepresented on the council and overrepresented among those appearing before the professional conduct committee, ${ }^{23}$ and in a recent session of the committee that I attended seven of the eight doctors appearing had qualified overseas.

\section{Overseas committee}

The overseas division of the GMC is its largest, with a staff of 53. Accounting for almost a third of the council's expenditure (over $£ 1 \mathrm{~m}$ annually), the division is self financing-raising its money from fees for limited registration and for the test set by the Professional and Linguistic Assessment Board (PLAB). The division is overseen by the overseas committee, which has 25 members (including two lay members) and meets twice a year. Most of the work is done by two subcommittees - the F committee, which supervises applications from overseas doctors for full registration, and the $\mathrm{L}$ committee, which oversees applications for limited registration.

One of the council's busiest divisions, it is accommodated in cramped conditions round the corner from the headquarters. Its work was expected to diminish as it became more difficult for overseas doctors to come to Britain because of increases in home graduates and changes in registration and visa requirements, but this has not yet happened (fig 1 ). ${ }^{4}$ The division continues to receive roughly 10000 letters each year from overseas doctors interested in coming to Britain; most are eligible for limited registration if they take the PLAB test; a few (mostly from American medical schools) are eligible for limited registration without taking the test; some are eligible for full registration; and a few are
London WC1H 9JR

Richard Smith, MB, senior

BrMed f 1989;298:1441-4 assistant editor ineligible because their qualifying examination is not recognised.

\section{Two tiers of registration}

The Merrison committee produced objective and subjective evidence to support its assertion that "there are substantial numbers of overseas doctors whose skill and the care they offer to patients fall below that generally acceptable in this country, and [that] it is at least possible that there are some who should not have been registered." It then went on to criticise the GMC for relaxing its standards to admit much needed overseas graduates into Britain: "We believe that the present unsatisfactory situation is principally to be attributed to a willingness on the part of the GMC to allow its duty as the protector of medical standards to be compromised by the manpower requirements of the NHS." That the council was lax in its standards when overseas graduates were desperately needed and is now harsh when they are not contributes to the impression among some overseas graduates that the GMC exercises a form of institutionalised racism. It also illustrates how the council may have put the health service's interest before the public interest.

Despite criticising the GMC the Merrison committee largely accepted the council's proposals for improving the system for registering overseas doctors, and the system proposed is essentially that which prevails today - a two tier system. Interestingly, the overseas committee would like to introduce a one tier system because it feels that the present system is unfair and over elaborate. Any change would require legislation.

\section{Full registration}

Full registration may be granted to graduates of 23 medical schools in Australasia, Hong Kong, Malaysia, Singapore, South Africa, and the West Indies (fig 2). To achieve full registration the doctors also have to be of "good character" and to have completed the equivalent of preregistration house jobs. Graduates from Australasian universities account for most of the overseas graduates granted full registration. (Since October 1987 British doctors wanting to practise in New South Wales have had to take a professional. and 